\title{
Article
}

\section{It's Personal: Biology Instructors Prioritize Personal Evidence over Empirical Evidence in Teaching Decisions}

\author{
Tessa C. Andrews* and Paula P. Lemons ${ }^{\dagger}$ \\ *Department of Genetics and ${ }^{\dagger}$ Department of Biochemistry and Molecular Biology, University of Georgia, \\ Athens, GA 30602
}

Submitted May 9, 2014; Revised October 28, 2014; Accepted October 31, 2014

Monitoring Editor: Debra Tomanek

\begin{abstract}
Despite many calls for undergraduate biology instructors to incorporate active learning into lecture courses, few studies have focused on what it takes for instructors to make this change. We sought to investigate the process of adopting and sustaining active-learning instruction. As a framework for our research, we used the innovation-decision model, a generalized model of how individuals adopt innovations. We interviewed 17 biology instructors who were attempting to implement case study teaching and conducted qualitative text analysis on interview data. The overarching theme that emerged from our analysis was that instructors prioritized personal experience-rather than empirical evidence-in decisions regarding case study teaching. We identified personal experiences that promote case study teaching, such as anecdotal observations of student outcomes, and those that hinder case study teaching, such as insufficient teaching skills. By analyzing the differences between experienced and new case study instructors, we discovered that new case study instructors need support to deal with unsupportive colleagues and to develop the skill set needed for an active-learning classroom. We generated hypotheses that are grounded in our data about effectively supporting instructors in adopting and sustaining active-learning strategies. We also synthesized our findings with existing literature to tailor the innovation-decision model.
\end{abstract}

\section{INTRODUCTION}

College biology instructors have been called upon to transform their teaching to improve student outcomes (American Association for the Advancement of Science, 2011), and to contribute to the goal of producing one million more highly qualified graduates in science, technology, engineering, and math (STEM; President's Council of Advisors on Science and Technology, 2012). One of the core suggestions for reform is replacing time spent lecturing with time engaged in active-learning strategies. Most simply, an active-learning

CBE Life Sci Educ March 2, 2015 14:ar7

DOI: $10.1187 /$ cbe.14-05-0084

Address correspondence to: Paula P. Lemons (plemons@uga.edu).

(c) 2015 T. C. Andrews and P. P. Lemons. CBE-Life Sciences Education (C) 2015 The American Society for Cell Biology. This article is distributed by The American Society for Cell Biology under license from the author(s). It is available to the public under an Attribution-Noncommercial-Share Alike 3.0 Unported Creative Commons License (http://creativecommons.org/licenses/by-nc-sa/3.0).

"ASCB ${ }^{\circledR}$ " and "The American Society for Cell Biology ${ }^{\circledR}$ " are registered trademarks of The American Society for Cell Biology. strategy is one in which the instructor stops lecturing and students work on a question or problem specifically designed to facilitate the construction of conceptual understanding. There have been many high-profile calls to incorporate more active-learning strategies (e.g., National Research Council [NRC], 1997; Boyer Commission on Education Undergraduates in the Research University, 1998; Handelsman et al., 2004), yet widespread transformation in undergraduate biology education has not been achieved. Most college science instructors still teach primarily or exclusively by lecturing (NRC, 2012). And those who have attempted to replace some lecture time with opportunities for active engagement may be unsuccessful at meeting the ultimate goal of improving student learning (e.g., Andrews et al., 2011). Additionally, facilitating the adoption and sustained use of active-learning strategies through teaching professional development has proven challenging (e.g., Ebert-May et al., 2011). Therefore, there is a critical need to better understand the process by which undergraduate biology instructors decide to incorporate active-learning teaching strategies, sustain use of these strategies, and implement them in a way that improves student outcomes.

One type of active-learning strategy is case study teaching. Case studies consist of real or realistic problems in 


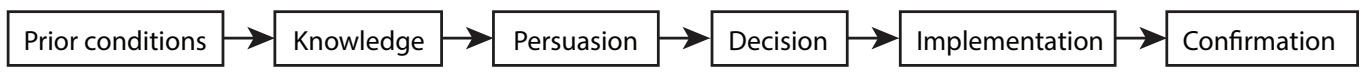

Figure 1. Innovation-decision model. Figure adapted from Rogers (2003).

science. Students working on a case collaborate with peers to integrate multiple sources of information and apply their knowledge to novel questions. Case studies come in many varieties but, ideally, they incorporate multiple active-learning strategies. Cases also often require students to consider ethical and societal issues that help them link their real lives to science (e.g., Herreid et al., 2011, 2014), which can influence student motivation (Glynn et al., 2007). Cases have been demonstrated to encourage students to make connections between science concepts and real-life situations (Lundeberg and Scheurman, 1997) and to facilitate the development of oral communication and teamwork skills (Lundeberg et al., 1999). Compared with traditional lectures, case study teaching improves retention of conceptual understanding and development of reasoning, problem-solving, and higher-order cognitive skills (e.g., Gabel, 1999; Dinan, 2002).

Case studies are a useful model system for examining how and why college biology instructors adopt active-learning teaching strategies, because many instructors are aware of and use case studies, many resources are available for case study teachers, and existing and new initiatives promise to continue to improve the availability and use of case study teaching in college science. The work of the National Center for Case Study Teaching in Science (NCCSTS; http:/ / sciencecases.lib.buffalo.edu) has contributed substantially to wide dissemination of case study teaching. The NCCSTS maintains a searchable and ever-growing repository of peer-reviewed case studies that instructors can download and use for free. The website repository includes 525 peer-reviewed cases and averages $\sim 10,000$ visits per day (N. Schiller, personal communication). Additionally, more than 18,000 users are registered for the Listserv, which announces new cases and training opportunities (Schiller, personal communication) The NCCSTS also provides biannual professional development meetings for high school and college instructors who want to learn more about case study teaching. In the past $20 \mathrm{yr}$, NCCSTS has provided teaching professional development for $\sim 6000$ teachers (Schiller, personal communication). Furthermore, the National Science Foundation recently funded a research network focused on case studies and problem-based learning that strives to further the accessibility, development, and use of case studies by linking multiple organizations that share this goal (http://sciencecasenet.org). Together, these initiatives lay strong groundwork for case study teaching to be widely adopted by college biology instructors.

A teaching strategy that an instructor has not used before, such as case study teaching, is an innovation for that instructor, regardless of how long the teaching strategy has been used by other instructors. Other disciplines, including sociology, communication studies, and public health, have a rich history of investigating why and how individuals adopt innovations. The current study is theoretically grounded in an empirically based model of innovation adoption called the "innovation-decision model" (Rogers, 2003). The innovation-decision model arose from investigations of how farmers in the 1950s adopted agricultural innovations, such as hybrid corn (Rogers, 2003). Since then, researchers have confirmed that the innovation-decision model is broadly generalizable to the adoption of many different innovations; it has been used to explain innovation adoptions as diverse as contraception and rap music (Rogers, 2003). The innovation-decision model has also been adapted to explain the experiences of $\mathrm{K}-12$ teachers who are required by their school to adopt a new curriculum (Hall and Loucks, 1978) and college physics instructors who adopt active-learning strategies voluntarily (Henderson, 2005; Henderson et al., 2012). ${ }^{1}$

The innovation-decision model consists of stages of change that individuals experience in the process of adopting (or deciding not to adopt) an innovation (Figure 1). These stages include 1) knowledge: when an individual becomes aware of the existence of an innovation and learns how it functions; 2) persuasion: when an individual forms an attitude (favorable or unfavorable) toward the innovation; 3) decision: when an individual engages in activities that lead to a choice to adopt or reject the innovation; 4) implementation: when an individual puts the new innovation to use; and 5) confirmation: when an individual seeks reinforcement of the decision already made (Rogers, 2003). An individual may decide to discontinue his or her consideration of or use of the innovation at any stage, including confirmation. In an extensive synthesis of the literature, Rogers (2003) identified four prior conditions that may be important to adoption of an innovation: previous practice, felt needs or problems, innovativeness, and norms of the social system.

The innovation-decision model has been used previously to better understand the process by which college instructors integrate new teaching strategies, such as active-learning strategies. Henderson (2005) conducted an in-depth investigation of one college physics instructor who was attempting to adopt active-learning strategies under promising conditions. Despite being motivated and having external support, this instructor struggled to maintain the use of the new strategies over the course of a semester. The key finding of this qualitative investigation was that the innovation-decision model needed to be tailored in the following ways to explain this instructor's experiences: the instructor made implementation decisions based on minimal knowledge and the instructor substantially altered all of the strategies he implemented (Henderson, 2005). The latter has been called "reinvention" in the innovation-adoption literature and is common across many types of innovations (Rogers, 2003). Reinvention is not inherently problematic, but the modifications instructors make to active-learning teaching strategies

\footnotetext{
$\overline{{ }^{1} \text { Henderson }}$ and colleagues investigated what they called "research-based instructional strategies," or strategies for which evidence of effectiveness exists. Most but not necessarily all of these strategies are active-learning strategies, according to our definition. To avoid confusion, we have used the more narrow phrase "active-learning strategies" when describing work that investigated research-based instructional strategies.
} 
may decrease the extent to which these innovations facilitate student learning. For instance, the modifications instructors make to peer instruction (Mazur, 1997), which is a type of active-learning instruction, often leave out key components that promote student learning, such as student-to-student interaction (e.g., Turpen and Finkelstein, 2009).

In another study, the innovation-decision model guided a large national survey $(n=722)$ that sought to better understand how physics instructors were using active-learning strategies (Henderson et al., 2012). Researchers determined what proportion of college instructors were at each stage of the innovation-decision process based on the instructors' self-reported awareness and use of active-learning strategies. They found that most instructors $(88 \%)$ had some awareness of active learning and thus could be said to be in or beyond the knowledge stage of the adoption process. Additionally, $72 \%$ of instructors had tried at least one strategy, meaning they had reached the implementation stage (Henderson et al., 2012). However, 32\% of those who had tried an active-learning teaching strategy later quit (i.e., left the innovation-decision process).

Some work has focused on what hinders and promotes faculty members in adopting and sustaining the use of active-learning teaching strategies. Instructors in the same national survey described earlier most commonly reported that lack of time and knowledge prevented them from using more active-learning strategies (Dancy and Henderson, 2010). Other studies confirm that lack of time is a barrier for teaching reform, as are lack of training and lack of incentives (see a review in Brownell and Tanner, 2012). For example, the project leaders of a highly successful, large-scale program to help faculty members change their teaching at one institution hypothesize that extensive support from disciplinary experts who are also trained in pedagogy and education research have been essential in helping more than 70 faculty members not only begin but also sustain the use of active-learning teaching strategies (Wieman et al., 2013). Taken together, these studies suggest that many faculty members try active-learning strategies; some abandon them; and time, knowledge, and incentives may be critical for supporting the sustained used of active-learning teaching.

Some research with undergraduate STEM instructors corroborates the importance of prior conditions in priming individuals for change. Specifically, dissatisfaction with teaching has been identified as a felt need or problem that conditions college instructors to change. Gess-Newsome et al. (2003) investigated three collaborating biology instructors who were externally funded to revise their shared course to better align with national calls for reform. This funding provided sufficient resources and time for the instructors to reform their teaching and contributed to a supportive teaching culture. However, ultimately, only one of the three instructors changed his teaching. This teacher's desire to change arose out of his sense (not his empirical investigation) that there had to be a better way to teach than to tell students information. In contrast, despite the efforts the other faculty members in the same study dedicated to revising the course, they did not fundamentally change their teaching, because they did not sense that their current methods were lacking (Gess-Newsome et al., 2003). Similarly, Bouwma-Gearhart (2012) found that science and engineering faculty members were motivated to pursue teaching professional development because of their personal perception that their teaching was relatively weak compared with their otherwise strong professional performance. In these instances, an instructor's self-image was critical in motivating change.

An instructor's self-image may also negatively impact his or her likelihood of investing time in adopting active-learning strategies. Brownell and Tanner (2012) hypothesized that professional identity is a key underlying reason why widespread education reform has not occurred in undergraduate STEM. Professional identity is how scientists "view themselves and their work in the context of their disciplines and how they accrue status among their professional colleagues as academic scientists" (Brownell and Tanner, 2012, p. 341). Professional identity is influenced by training, peers, and the everyday culture of our work environments. Professional identity may act as a barrier to adopting active-learning strategies, because scientists are trained, both explicitly and implicitly, to think that research is more highly valued than teaching in academia and that scientists must choose to be researchers or teachers rather than making the choice to equally emphasize both in their careers (Brownell and Tanner, 2012). These tensions between teaching and research may lead instructors to view teaching professional development and teaching innovations with skepticism, and they may be unlikely to invest time in changing their teaching, even if time were made available and change was incentivized (Brownell and Tanner, 2012).

As we have summarized, existing research has confirmed that the innovation-decision model is a useful initial framework for thinking about college instructors' adoption of active-learning teaching strategies, and it has provided insight about what influences undergraduate STEM instructors as they make teaching decisions. We are adding to that an indepth analysis of a substantial sample of college biology instructors who vary in their years of teaching, experience with active learning, and institution type. We have sought to uncover any and all factors and conditions that may be important in the process of adopting and sustaining active-learning instruction. This is the first of multiple studies that should be done to ensure that we have fully captured the experiences of instructors as they adopt teaching innovations. This work will be an initial step toward the ultimate goal of identifying what reform seekers-professional developers, administrators, and instructors themselves-can do to facilitate the long-term adoption of teaching strategies that produce better student outcomes than lecturing alone.

\section{METHODS}

\section{Recruitment}

We investigated a cohort of biology instructors who attended a professional development conference on case study teaching in science. We recruited participants from this conference, rather than from the broader population of biology instructors, in order to target instructors who had already committed some resources (e.g., time, money) to learning more about case study teaching and therefore were likely to be-at the very least-seriously considering implementing case study teaching. The professional development conference was held over a 2 -d period, and $~ 100$ case study teachers in several STEM disciplines attended. The conference 
included workshop tracks for both veteran and novice case study instructors and plenary speaker and poster sessions in which veteran instructors presented their case study instruction. This diversity allowed us to recruit instructors with a range of case study teaching experience.

We recruited participants through the conference organizers. The organizers sent an email to all registered participants $2 \mathrm{wk}$ before the conference, explaining the project and asking for volunteers for a 1-h interview. During the conference, one of the authors (P.P.L.) made an announcement following the opening plenary speaker, again explaining the project and asking for volunteers. To accommodate travel plans, we interviewed participants over a 3-d period: before, during, and after the conference. This research was conducted under exempt status at the University of Georgia (IRB project 201310146-0).

\section{Participants}

The participants included 17 biology instructors from a range of institution types and at various stages of their careers (Table 1). The participants also varied in their experience with case study teaching: experienced instructors had more than 2 yr of experience implementing cases, intermediate instructors had no more than 1 yr of experience, and new instructors had never used formal cases (Table 1). Pseudonyms are used throughout the paper to protect the anonymity of research participants.

\section{Data Collection and Analysis}

We used semistructured interviews with interview questions designed to elicit participants' perceptions of their personal process of instructional change. In a semistructured interview, interviewers use a set list of questions but adapt the delivery of the questions to maintain a natural flow of conversation with the interviewee (Patton, 1990). This structure maintains the freedom to probe further to explore an idea raised in a participant's answer. Building on the innovation-decision model, we asked questions to evoke participants' ideas regarding motivation for adopting case study teaching, learning about case study teaching, forming an attitude about case study teaching, implementing case study teaching, and anticipated or realized barriers and affordances to the continued use of cases (see Supplemental Material Appendix A for a complete list of interview questions). We appropriately tailored questions for interviewees who had not yet implemented case studies and for interviewees who already used cases. Before interviews began, we also generated an a priori list of ideas (hereafter referred to as categories) that we expected instructors to express based on the innovation-decision model and other existing research.

Each author conducted approximately half of the interviews, and each interview was audiotaped. Verbatim transcripts were developed from each audio recording. We then analyzed these transcripts using inductive content analysis (Patton, 1990). The goal of the analysis was to identify and richly describe the factors and conditions that instructors perceive as influencing them as they start, sustain, and improve their use of case studies. Our data analysis took place in three phases.

\section{Phase 1}

The goal of the first phase was to expand our a priori list of ideas we expected instructors to express about their experiences in the innovation-decision process based on our initial impressions of the interview data. We designed and implemented a collaborative interview procedure to begin initial data analysis during the 3-d interview period. To begin analyzing and synthesizing the interviews we conducted, we each took detailed field notes during interviews. Within $24 \mathrm{~h}$ of each interview, the interviewer also reflected on the interview and her field notes and wrote a summary of the ideas

Table 1. Instructor's background and experience with case study teaching, ordered from most to least experience

\begin{tabular}{|c|c|c|c|}
\hline Pseudonym & Carnegie classification $^{a}$ & Position & $\begin{array}{l}\text { Case study teaching } \\
\text { experience }\end{array}$ \\
\hline Donna & Public, associate's & Full-time instructor & Experienced \\
\hline Lisa & Private, not-for-profit, baccalaureate & Associate professor and administrator & Experienced \\
\hline Pamela & Public, research university & Associate professor & Experienced \\
\hline David & Public, 2-yr, associate's & Assistant professor & Experienced \\
\hline John & Public, 2-yr, associate's & Associate professor & Experienced \\
\hline Linda & Private, not-for-profit, baccalaureate/associate's & Part-time instructor & Experienced \\
\hline Lori & Public, associate's & Full-time instructor & Intermediate \\
\hline Karen & Private, not-for-profit, baccalaureate & Assistant professor & Intermediate \\
\hline Susan & Private, not-for-profit, master's college and university & Assistant professor & Intermediate \\
\hline Mary & $\begin{array}{l}\text { College preparation program within a public master's } \\
\text { college and university }\end{array}$ & $\begin{array}{l}\text { High school-to-college transition } \\
\text { teacher }\end{array}$ & Intermediate \\
\hline Debra & Public, master's college and university & Full-time instructor & New \\
\hline Cynthia & Private, not-for-profit, baccalaureate & Full-time instructor & New \\
\hline Brenda & Public, research university & Associate teaching professor & New \\
\hline Cheryl & Public, associate's & Associate professor & New \\
\hline Patricia & Private, for-profit, master's college and university & Associate professor and administrator & New \\
\hline James & Private, not-for-profit, research university & Professor & New \\
\hline Robert & Private, not-for-profit, baccalaureate & Professor & New \\
\hline
\end{tabular}

${ }^{a}$ Our sample included two international colleges and universities for which a Carnegie classification was not available. In these instances, we used the institutions' websites to determine classification. 
expressed by the interviewee, as well as notes about parts of the interview that stood out. We were careful to document when participants said things that were relevant to our theoretical framework, not predicted by our theoretical framework, similar to other interviews, or different from other interviews. We conferred with each other regularly throughout the 3-d period of interviewing to discuss ideas emerging from the interviews. Additionally, we reviewed each other's summary of each interview to stay abreast of any details not explicitly discussed. After the 3-d interviewing period, each author listened to the audio recordings of interviews conducted by the other author and added her own perceptions to the summary. We did not analyze these summaries further, but the process of writing and discussing them helped us to integrate and synthesize ideas from the interviews and add to our a priori list of categories. This list of categories, which was grounded in the data emerging from the interviews, as well as in existing literature, served as the starting point for a systematic analysis of the interview transcripts in phase 2 (see full list in Supplemental Material Appendix B).

\section{Phase 2}

The goal of the second phase was to capture and categorize the diversity of ideas participants expressed about case study teaching. This process is generally referred to as initial coding, open coding, or in vivo coding (Charmaz, 2006; Saldaña, 2013) and is characterized by remaining "open to all possible theoretical directions indicated by your readings of the data" (Charmaz, 2006, p. 46). In phase 2, we annotated each transcript by identifying quotes that expressed an idea represented by one of our a priori categories from our initial list. One quote could express ideas that belonged in multiple categories. Throughout this analysis, a priori categories were revised to better align with the data, and new categories were added to the list. For example, though our a priori list included a category about supportive colleagues that was appropriate for many quotes, we also added a category about instructors feeling that interactions with their colleagues were useful, because this idea was also emphasized by instructors and was distinct from more general quotes about the supportiveness of colleagues. We also added categories that represented ideas not present in our a priori list of categories. We added a category called "My experience trumps research," because we repeatedly observed instructors downplaying the role of empirical evidence in their teaching decisions and prioritizing the role of their personal experiences. Each time we identified a new category, we reanalyzed each transcript, looking for quotes that fit in that category. We worked collaboratively to analyze each interview transcript in Atlas.ti7 (product of ATLAS.ti Scientific Software Development). Working together allowed us to continually discuss our impressions of the data and immediately refine our list of categories and category descriptions and resolve ambiguities.

After analyzing all interview transcripts through this iterative process, we revised and further defined the list of categories by reading all of the quotes within a category to see whether they shared definable features. We also looked for similarities among closely related categories to see whether these could be consistently distinguished. If not, we combined and redefined categories. We omitted categories from our initial list that were never used in the analysis of interview transcripts. For example, we began with an a priori category called "observability" based on the innovation-decision model, but this idea was not present in our interview transcripts and therefore was omitted from our final list of categories. In other cases, a category generated during phase 1 was too simplistic and needed to be divided into several categories to capture the diversity in our data. The outcome of phase 2 was a final list of categories representing the ideas expressed by instructors, with detailed descriptions of each category and quotes illustrating the range and depth of the category. Our final list contained more than twice as many categories as our initial a priori list (Supplemental Material Appendix $\mathrm{C}$ and Figure 2).

\section{Phase Three}

The goal of the third phase was to rebuild the disassembled data produced during previous phases into conceptual themes. This stage of text analysis is referred to as axial coding (Saldaña, 2013) and involves organizing categories into broader conceptual categories and determining which categories are the dominant ones and which are less important. This step is grounded in research questions but may also reveal the limitations of these questions. We began this investigation with specific research questions that focused on different steps of the innovation-decision process, but these questions ultimately provided a limited and insufficient framework for capturing our data. This became evident as we began to group categories into conceptual themes. As we did so, we discovered that a single overarching theme best captured our data, necessitating a reorganization of our data into the final objective for this paper. That is, personal experiences promote or hinder instructors in adopting, sustaining, and improving their implementation of case study teaching.

In phase 3, we also sought to understand the support needed for case study instructors at different stages of the adoption process. For this analysis, we compared experienced and new instructors (Table 1) but did not include the intermediate instructors, as the intermediate group included only four instructors, and we thought we would find the most differences between experienced and new instructors. We counted the occurrence of quotes in each category within the two groups of instructors. Owing to the small sample size, we only report the most striking differences, that is, when almost everyone in one group was represented in a category compared with almost no one in the other group.

\section{RESULTS}

We describe and illustrate our findings with quotes from our interviews with instructors. While we have endeavored to present the participants' responses exactly as stated, we have lightly edited some quotes; these changes are clearly indicated by inserting clarifications in brackets or using ellipses to indicate excluded, irrelevant information. Most often, clarifications consist of inserting nouns in place of pronouns. Quotes are indented and attributed to the speaker via pseudonym. 


\section{INTERVIEW TRANSCRIPT}

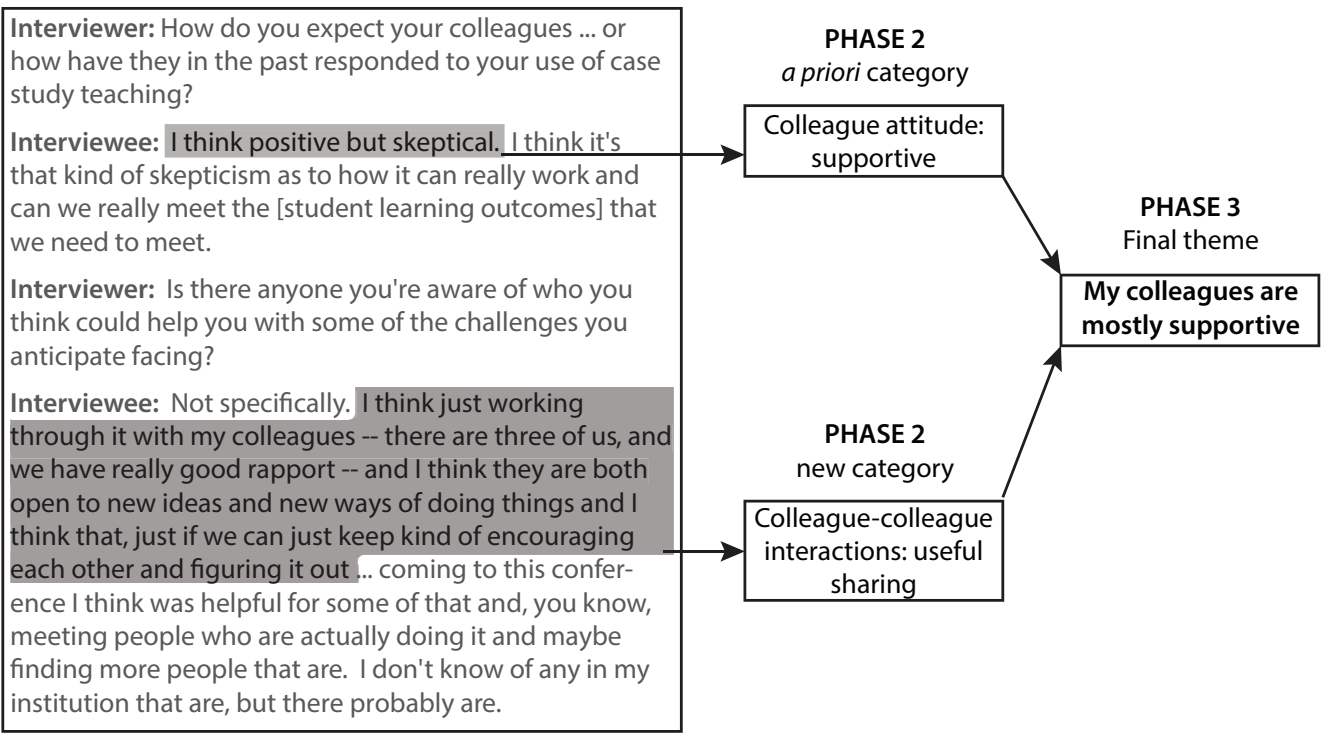

Figure 2. Excerpt of an interview transcript illustrating phase 2 analysis and its relationship to the format of final themes in phase 3 . In phase 2 , we categorized quotes from the interviews using our phase 1 a priori list and new categories identified during phase 2 . In phase 3 , we organized categories into final themes, which are presented in the Results.

\section{Personal Experience Overarches the Process of Adopting and Sustaining Case Study Teaching}

We expected to find that instructors in our sample were influenced by affective factors, such as their sense of dissatisfaction with teaching (Gess-Newsome et al., 2003; Bouwma-Gearhart, 2012). On the other hand, because all the instructors in our sample were trained as scientists, we expected they were equally or more influenced by empirical evidence. After all, scientists value data. One of our participants, Susan, succinctly expressed the popular notion that empirical evidence is an effective way to convince science instructors to include more active learning in their teaching:

They are scientists, so I think if you show them enough data, they will understand ... so I think if I show them data, I'd say "Look at the studies that show how much students are interactive and how much they retain relative to other studies." That might at least have them buy in a little bit. (Susan)

However, when we probed instructors about the type of evidence they had seen regarding case study teaching, we learned that they relied mostly on personal perceptions and experiences about case study teaching. They did not depend on empirical evidence. For example, James was convinced to use case studies not because he had read any primary education research but rather because of hearsay about the educational research and his gut feeling that being active is a more effective way to learn than sitting and listening:

I don't personally have any [evidence], because I guess I believe all the studies [of case study effectiveness] . . . and I don't even know the studies. I just hear people talk about generally the results in education research, that this small group and discussion and engagement ... student engagement or learner engagement, or whatever the jargon is. I don't know [what] the jargon in education is, but getting them engaged and involved and actively participating has to be more effective than sitting and trying to soak something up or just reading. I don't need to prove anything. I have a gut feeling that's correct. (James)

James was unapologetic for accepting empirical findings about case studies without reading or evaluating them for himself.

In contrast, some instructors had read, or at least seen, articles from the primary literature on case study teaching. But these instructors discounted the importance of empirical studies compared with the importance of personal experiences with case study teaching. For example, Karen had read some empirical research on case study teaching, but her primary evidence was personal experience:

I am like most other undergraduate bio instructors, in that I don't read a lot of literature, but that being said, I have seen some of the literature about the effectiveness for students, both understanding and retention of the material. My primary evidence has been experience. [Case study teaching] is a strategy that has worked well for me in the past, and it's a strategy that ... students respond positively to . . . and they seem to have fewer concerns about the material going into exams. They seem to do better on exams. (Karen)

Still other participants acknowledged that they had formed their attitudes about case study teaching in unscientific ways. Like Brenda, they seemed somewhat apologetic about their unscientific approach but emphasized the personal experiences that had persuaded them that case study teaching is effective: 
Table 2. Personal experiences that promote or hinder case study teaching ${ }^{a}$

\begin{tabular}{ccc}
\hline Category & $\begin{array}{c}\text { Number of } \\
\text { participants }\end{array}$ & Illustrative quote \\
\hline
\end{tabular}

Personal experiences that promote case study teaching

Self-considerations

I hate lecturing.

Case studies are a good fit for me.

I'm willing to try and fail.

Interactions with other people

Students are more engaged in class and learn more when I use case studies.

My colleagues are mostly supportive. $^{\mathrm{b}}$

My administrators are supportive.

Contextual factors

I need teaching materials.
17 supportive 6 unsupportive 6 ambivalent

I hate lecturing. I do it all the time and I hate it, and at the end of every hour I feel like, well that sucked. (Cheryl)

[Case studies appeal to me because] I can use my background so effectively, and part of it is that it makes a very real world. We're not just sitting in this classroom, we're learning a skill that is going to be something useful to the world. (Debra)

I mean, I don't expect it to be perfect this year. I know that going into it. We'll just kind of see how it goes, and then know that I can revise it for next time. (Brenda)

As much as I try to be interactive when I lecture and ask the students questions, it doesn't require all of the students to answer the questions, so I feel like case studies are more likely to ... get everybody involved ... I think generally it's just more interesting for the students. (Brenda)

You know, there is a range of faculty members and ages and pedagogical methods. Some people are very enthusiastic about [case study teaching]. Other people are supportive and they are fine with it, but they are very much committed to lecture, so they are less interested, although they are supportive of me doing it, not particularly interested for themselves. (Karen)

[My administrators] are supportive in the fact that they paid for me to come here, so, I mean, I think it was around $\$ 3000$ when everything was said and done. (Lori)

Personal experiences that hinder case study teaching

\section{Contextual factors}

I do not have enough time to prepare for class.

I have to balance case study teaching with covering enough content.

I do not feel sufficiently prepared for case study teaching.
6

6

8

My habit until now has been sort of I look at what my lectures are that are coming up and I know that the students aren't going to be terribly excited, so I'll search through the case studies to see if I can find something that will spark them a little bit and then bring that in. It hasn't been ... It's not integrated into my syllabus per se, it's more [an] ad hoc kind of a thing. (Donna)

10

a Data include number of participants who expressed each idea and illustrative quotes.

${ }^{\mathrm{b}}$ All 17 participants reported having supportive colleagues. Additionally, 12 of the 17 participants also reported having unsupportive (six participants) or ambivalent (six participants) colleagues.

I can't say I've really looked for it [evidence].... You know, I sort of feel like ... this isn't very scientific, but I sort of feel like it's more fun, the students are more engaged and I feel like they learn the material. That's not very scientific, but you know; it's better than me standing up there and lecturing. (Brenda)

Finally, some instructors, like Pamela, did not even mention empirical studies when we asked them what evidence they had seen regarding case study teaching:

I have seen only positive things. I've seen learning, loosely defined . . . I've seen that years later they [students] can still remember things. I've seen former students who still remember, like baroreceptor reflex, because I had it on all five case studies. (Pamela)
In summary, of 17 instructors, 16 deferred to personal experiences to explain their rationale for choosing case studies. These data suggest that, contrary to Susan's and other reformers' beliefs, using data to convince instructors to change is ineffective. Instead, our data suggest that instructors prioritize personal experiences in their decisions about teaching innovations. Therefore, we used this overarching theme as a lens through which to view our entire data set. We identified personal experiences that promote case study teaching and personal experiences that hinder case study teaching. These experiences are summarized in Table 2 and further elaborated in the remainder of the Results. For the purpose of this research, we define personal experiences as practical contact with and perceptions of events and people, including oneself. 


\section{Personal Experiences That Promote Case Study Teaching}

We sought to uncover the range of personal experiences that could account for participants' decisions to start, sustain, and improve their use of case studies. We identified self-considerations, interactions with other people, and contextual factors that pushed our participants toward initiating, sustaining, and improving case study teaching.

\section{Self-Considerations}

Concerns about personal satisfaction and self-image as a teacher motivated instructors to use case study teaching. Additionally, instructors noted that cases are compatible with the ways they have naturally taught. Some instructors in our sample also reported that they were able and willing to tolerate the ups and downs of implementing a new teaching strategy.

I Hate Lecturing. Some participants used case studies to escape lecturing. Among the most animated responses instructors provided in our interviews were those that pertained to dislike for lecturing. Some instructors described lecturing as boring:

To me, this whole idea [of case study teaching] is great, because straight lecturing is so boring. Unlike Alfred who said he enjoys lecturing, I just think it's boring. If I'm bored, the students are doubly bored. (James)

Other instructors went so far as to say they hate lecturing:

I hate lecturing, I actually do. I will lecture every day for about 20 minutes, and then I get sick of it. I figure if I'm getting sick of it, they're going to get sick of it. (Linda)

Not all instructors had such strong negative feelings about lecturing but still felt that case studies were more fun for them and for the students. For example, one instructor had been lecturing for more than $10 \mathrm{yr}$ and had grown increasingly weary of his teaching responsibilities. At the time of the interview, he was planning to begin to incorporate case studies and anticipated the following:

I think it's a lot more fun to teach that way. I think that I will be more enthusiastic about my teaching or excited about it, and I will be learning myself in the process, which will make me a better teacher, and then I think the outcomes for students will be superior. They will be more engaged and more interested in coming to class. (Robert)

While we were not surprised to learn that instructors prioritized their own needs, we were surprised that one important concern was simply enjoying their teaching more.

Case Studies Are a Good Fit for Me. Some instructors in our study emphasized the importance of fit between an instructor and the teaching strategies he or she uses. One instructor brought this up when we asked how she made decisions regarding the design of a course.
First and foremost, it has to fit my personality. I think that's true about any instructor. This will work well for some and will not work well for others. (Debra)

One instructor new to case study teaching felt that she could better be the sort of teacher she wanted to be using case studies compared with only lecturing and that this would alleviate some of the nagging dissatisfaction she felt about her teaching:

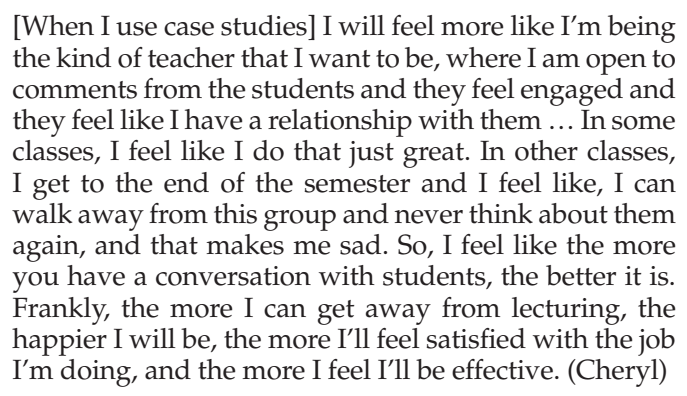

A few instructors reported that they had used something similar to case studies before they had learned about formal cases, and they did so because it seemed like a natural teaching practice to them:

I didn't get a book, I didn't go online, I didn't go to a conference, I just have always known or understood the value [of case studies], and I have always tried in whatever I teach to apply it to the real life, real world, so that has always been, I guess, a teaching philosophy. (Pamela)

I'm Willing to Try and Fail. Someone could hate lecturing, but never change his or her teaching if he or she is uncomfortable with potential failure. However, some instructors in our study actually indicated a willingness to practice trial and error. In fact, they seemed to expect that new teaching strategies might not work well the first time and must be refined from one class period to the next or one semester to the next. For example,

\begin{abstract}
A lot of the case studies I use, sometimes I use them as is and they're not perfect, but I just kind of suck it up and go along, but it just takes time to make them your own and the way you want to teach them. Like the sea otter one, I've been doing for four years. When I started, the first thing I did with it was sent [sic] it home as homework, and that was a disaster. Then I realized case studies are not meant to go home. (Linda)
\end{abstract}

\section{Interactions with Other People}

In addition to considering their own inclinations and desires, instructors' personal experiences with other people influenced their decisions to start, sustain, and improve their use of case study teaching. Students strongly influenced instructors. Specifically, instructors reported being motivated by the positive impact they felt case study teaching had on student outcomes. Instructors perceived their colleagues to be mostly supportive of their use of case studies, but colleagues' 
perceptions of case study teaching influenced only some instructors, and administrators had even less impact.

Students Are More Engaged in Class and Learn More When I Use Case Studies. All instructors seriously considered student outcomes in their decision-making process about case study teaching. They felt that case study teaching added value to their teaching. This is another example of instructors' reliance on personal experience over empirical evidence: instructors' reports of positive student outcomes were based almost exclusively on their personal perceptions, not on systematic investigations of case study teaching compared with other teaching strategies. Instructors reported that student engagement in class was improved by case study instruction:

Of course, all anecdotal, but I find that my students tend to come to class a little bit more excited. (Donna)

Karen explained how she observes whether a case study is effective based on how actively students are talking with each other:

A case goes well if my students are engaged the whole time we're talking about it, if it challenges them. What I want to see is, I want to see a level of challenge where the students are actively talking with each other, they are trying to problem solve, they are trying to figure out answers. (Karen)

In addition to engaging students in class, instructors felt that using case studies had improved student learning:

I can always, at some point, see the shift and see the light bulbs that are going off, so I know what works. Also, they write answers and they hand them in, or they discuss it or present it. I'm like, whoa. So observing what they are getting out of it in terms of what they are giving me, what they are telling each other. (Pamela)

Instructors' perceptions were also strongly shaped by what students say to them about cases, both in person and on endof-course evaluations. Instructors appreciated that students valued case study instruction and liked case studies:

\begin{abstract}
Anecdotally, I saw a real change, especially once I was able to modify my instructions and get maximum buyin. I saw noticeable changes in frequency of certain types of interactions with students. Traditionally, it wasn't uncommon for me to get students late in the semester [saying to me], "Do you teach the next course in the sequence? We want to have you again." Once I started using the cases a lot, I started to get that question the second and third week, not just one or two students, but groups of students would come to me just a few weeks into the course and asked who teaches the next class, where, at that point in the semester, there may not have even been but one test, they may not have even done all that well on that test. It wasn't a case of I'm getting an easy A with you and I want more. It's regardless of what grade I'm getting, I like what we're doing here. (John)
\end{abstract}

Some instructors anticipated negative feedback from students about case study instruction, and this also affected the decisions they made. For example, David explained how he would respond to negative feedback from students:
If I go back and ask [students], "Hey, just attended this case study conference and want to get your ideas on this." And they all say, "No way," then that will definitely be a hindrance to me doing it. I will have to think long and hard about what I want to do there. Just because they say no, I know it doesn't make it something that shouldn't be done, but I will have to think about maybe how to present it to them in such a way that they like it better. (David)

In other cases, negative feedback from students had the effect of motivating instructors to try case study teaching. For example,

\begin{abstract}
The students have made it clear ... I hear them talking at the end of class ... oh, this is such a long class ... oh, I hate lectures. I'm thinking, "Okay, I've got to do something different." I've been working really hard in the first two sessions breaking it up, having them do activities, but you can only do so many activities that really are not just busy work, so I want to do something that puts them in charge of their learning and makes them do more of the work. (Cheryl)
\end{abstract}

My Colleagues Are Mostly Supportive. Research on the adoption of innovations has found that peers are a particularly valued source of information when an individual is forming an opinion about an innovation (Rogers, 2003). Individuals may form an opinion more quickly if they have access to the opinions of peers, because they trust that their peers' experiences with an innovation will be similar to their own experiences. Therefore, we sought to understand the role of colleagues in instructors' decisions to start, sustain, and improve case study teaching. Colleague perceptions were not an important influence for many, but generally instructors perceived their colleagues to be supportive of their use of case study teaching.

All instructors had at least some colleagues who were supportive of their use of case studies, and these colleagues provided various services for instructors, such as acting as a sounding board for new ideas, providing solutions to specific problems, and providing confirmation and encouragement. For example,

I talk to a lot of colleagues about what they do and how they do it and why. There's a math colleague that uses a lot of inquiry ... spends a lot of time, like, manipulating the class as it goes based on the students that are in the room, so I do talk to him. I've sat in on his class, too, and say, like, "How did you get them to do that? Do they freak out when you do that because you really call them out a lot?" (Cynthia)

Additionally, some instructors were attending the professional development conference at the advice of another instructor or a coteacher:

A friend of mine and colleague at work had done the weeklong training conference, and she was, sadly, retiring, and she was very good in the classroom experience, so I was chatting with her about the case study approach in the lab ... and she recommended, rather than trying to describe all the details, that I come here [to the professional development conference] and hear it from the people who have the training materials. (Debra) 
In a few instances, as illustrated with John, supportive interactions with colleagues had been instrumental to an instructor's persistence in the use of case studies:

I think it was just the two of us working together and trying to improve our results. I think, over time, we dragged other people into it, but it was mostly our motivation as the younger untenured faculty to keep pushing ourselves forward. (John)

Furthermore, some participants had the experience of being instrumental in encouraging another instructor to use case studies:

\begin{abstract}
When [new instructors] come in and are teaching two new classes and they have no materials, I'm happy to share everything I have. I give a big folder, put [it] on the USB drive and say, here you go ... So they're being introduced to case studies on the front end, and a lot of people that we have hired have had limited teaching, especially in this particular area, so I think they have been willing to take any resource they have and try it, and it has evidently worked for them to some extent. (David)
\end{abstract}

While most instructors had colleagues who had supported their adoption of case study teaching, a few instructors had some colleagues they perceived to be unsupportive. In all but one of the cases, the instructors downplayed this influence, perhaps because they were tenured like Cheryl, an associate professor in our sample:

\begin{abstract}
I have some colleagues who tend to be the kind of people who act like they know everything. They are very rigorous, they do everything by the book, and they will feel like I am watering things down. I'm pretty sure that at least one of them, possibly two of them, will say you're not really covering the material ... and I'm old enough that I'm not very intimated by that anymore. I would have been at one time. (Cheryl)
\end{abstract}

On the other hand, Susan, a junior faculty member, seemed very concerned that a senior colleague was wary of her use of case study teaching:

I feel like there will be a bit of resistance from my colleagues because perhaps they have not had the best experiences ... I do see that as a bit of a barrier. (Susan)

Some instructors reported that their colleagues were ambivalent about teaching and therefore had no influence on instructors' decisions about case studies:

Okay, this is going to sound terrible. My colleagues
don't care. (Brenda)

My Administrators Are Supportive. Another potentially influential type of personal experience is instructors' perceptions of and interactions with the administrators with whom they work. Administrators may have control over resources and teaching responsibilities, and they may guide retention and promotion decisions, making them highly influential in the life of a college instructor. Overwhelmingly, instructors in our study felt that their administrators were supportive of their use of case study teaching, but this was not a strong influence on their decisions about case study teaching. However, one important form of support that several instructors had received was funding for the professional development conference at which our interviews were conducted. For example,

My administrators were the ones who were gung-ho in favor of me going [to this professional development conference]. When I said I want to do this, they said, "You go. We'll get the money." (Cheryl)

Some instructors assumed that their administrators were supportive of case study teaching, because it fell within the scope of broad teaching reform initiatives on campus:

\begin{abstract}
I think that [using case studies] would be a good thing, because ..., what's the catch term for this?high-impact practices? [Administrators] talk about those all the time. They don't always want to pay for them ... They love to give presentations about high-impact practices and try to say when they're working or not working through survey data of the whole student body, which is hard, I think, but I would say it is encouraged on our campus. (Cynthia)
\end{abstract}

Perhaps because case study teaching aligned with larger reform efforts on campus, a few instructors thought that using case studies would be viewed favorably during the review process for promotion and tenure:

I'm actually [up] for my third-year evaluation right
now. I expect actually that [case study teaching] will be
well received. I'm at a private, liberal arts undergrad-
uate institution, and the focus is very much on teach-
ing. And they tend to be very supportive of anything
you're doing in the classroom that indicates you are
thinking about ways to accomplish your educational
sort of goals and trying new things, so I would expect
case studies would fall under that category. (Karen)

\section{Contextual Factors}

In addition to the influence of self-considerations and interactions with other people, instructors' decisions to start, sustain, and improve case study teaching were influenced by the practicalities of their job responsibilities. Though the educational value of case studies was crucial to instructors, the fact that so many case studies are freely available online made it convenient for instructors to incorporate case studies when they needed materials for their course. Some job practicalities also hampered case study teaching. While these practicalities pertain to the instructor and could be construed as self-considerations, we called them contextual factors instead, because they have to do with job constraints rather than personal satisfaction or self-image. We describe these further in the next section.

The primary contextual factor that promoted case study teaching was the need for teaching materials. Some instructors initiated case study teaching because new teaching responsibilities had left them feeling desperate to try anything but lecturing: 
My very first class outside of graduate school was the non-majors class, and I was really struggling, because I realized that, number one, I wasn't teaching to their level and I didn't know how to, because the only people I had ever really taught with were people like me, other graduate students or other faculty in my discipline ... so I realized that I was really struggling with how to speak to these people and get the point across and get them educated without just totally blowing their mind, which I didn't necessarily succeed at real well. So I got case studies, and I focused on the case studies that were specifically geared toward non-majors to help me. And it was really good, and they loved it, even though they had a lot more work. (Susan)

Upcoming teaching responsibilities also provided the opportunity for instructors to begin using case studies or to increase their use of case studies. Some instructors in our study were more willing to make new teaching plans that involved case studies than to revise existing courses to include case studies. However, instructors also used case studies when they needed teaching materials to fill class time, engage student interest, or meet a specific learning objective within ongoing courses. For example, some instructors, like David, chose case studies to complement their lecturing, because they felt that lecturing alone would bore students:

\begin{abstract}
The problem is, though, if you've got to teach that Thursday class and you've got an 8-10:50, so a 3-hour window, you cannot lecture 3 hours. I mean, you can, but they're going to hate you, so my goal was initially probably trying to find some times ... when I didn't have a lab ... trying to find something that would break up the monotony of the class and to still teach a point that we were trying to teach in class. Like I say, it was probably a little self-serving at first to be perfectly honest. Not that I had bad intent. If I brought them good case studies, they will learn something from it, but I know I can't lecture 3 hours. And I'm not going to try that. I started using case studies that way. (David)
\end{abstract}

\section{Personal Experiences That Hinder Case Study Teaching}

Instructors in our study spent substantially more time talking about the personal experiences that promoted their use of case study teaching than talking about barriers they perceived. We may have selected for this tendency by targeting instructors who were attending professional development for case study teaching. For example, when we asked one instructor (Pamela) about barriers to case study teaching she responded, "I don't like to think in barriers." An instructor who perceives more barriers than affordances may be less likely to invest time in professional development. Despite their optimism, the instructors we investigated described three contextual factors that presented challenges as they started, sustained, and improved their use of case study teaching: lack of time, trade-offs between covering content and using case studies, and lack of expertise in case study teaching.

I Do Not Have Enough Time to Prepare for Class. Most instructors mentioned that time was a limiting factor in case study teaching and therefore impacted their decisions about case study teaching. Instructors needed time to prepare to teach case studies, especially when using a case for the first time. Insufficient preparation time sometimes resulted in a case study failing:
There are cases that crash and burn ... honestly, it usually happens when I'm short on time and I need to pick a case quick and I find one that works and I don't take the time to modify it for my particular situation. You know, it just means there are questions that might be less focused on what I'm actually trying to accomplish or questions that maybe my students ... we haven't really addressed what they need to know in order to grasp the importance of those questions. (Karen)

Sufficient preparation time was a real and constant teaching challenge for the instructors in our study. However, they overwhelmingly viewed the time investment required for successful case study teaching to be worthwhile:

It's a ton of work making a case, but I don't mind that
if it's engaging enough. It's a ton of work making a
lecture that works well, too, so it's the same deal. It's
going to be a lot of work for about 10 years, so it seems
like to me it's teaching until you get enough scripts
going and you can pull from different things and you
learn more confidence and discussion in the classroom
and you feel that all the questions that are mostly go-
ing to emerge. It's like any other method. You get out
what you put in. (Cynthia)

I Have to Balance Case Study Teaching with Covering Enough Content. Case study teaching not only requires an instructor to spend time preparing for class, it also requires more class time than a lecture on the same concept. Instructors who had already used case studies recognized this fact, and some discussed how they grapple with the trade-offs between covering more content versus using case studies:

If I'm using [case studies] more extensively, I don't know content wise that I can get all the content across. It's like a little demon inside you kind of going, how do I handle this? Do I have to cover everything, or do I have to cover what's most important? Even if I'm covering everything, I'm just lecturing on it. Are they getting it? If I cover what's most important, am I still accomplishing the goal for the class? So I'm dealing with that demon a little bit in terms of, there's a lot [of] things that are essential, so doing $100 \%$ case studies would be really hard. Doing lecture with case studies or like a flipped class I think would accomplish that, so I've got to look at-are they going to learn everything they need to know to go on to, for instance, nursing school? That's a real concern that I have. (David)

Mary, who had been using case studies for about a year, felt that covering a lot of content and using case studies were incompatible. However, case study instruction helped her meet learning objectives she valued more highly than content coverage:

Well, [case study instruction] slows things down. You go through fewer concepts, but you go into more depth, and I think that it has a more lasting impression, because now you are requiring students to think, you are requiring students to apply things ... if your goal is content coverage, it's going to slow you down ... If that is a major goal, you wouldn't be able to do it. (Mary) 
Some instructors recognized that prioritizing content coverage was the status quo in their department. For example, Debra, who was new to case study instruction, expressed concerns about finding a suitable balance between using case studies and meeting the expectations she and the rest of her department had for what content must be covered in a class:

[My colleagues] will all be concerned whether the content is still being covered, and the quality of the program is very important to them. They want to make sure that, if [students are] moving on to somewhere else, is the [content] being covered? (Debra)

I Do Not Feel Sufficiently Prepared for Case Study Teaching. Instructors also viewed insufficient pedagogical preparation as a hindrance to their use of case studies. Despite a willingness to use trial and error, instructors in our sample worried that they lacked the full set of skills and strategies needed for effective case study teaching. For example, some instructors felt their experience lecturing had not prepared them for managing a case study class, which typically relies heavily on discussion and group work:

I still am struggling with how to run a good discus-
sion and also how to ... keep them on task, how to
make sure they are all accountable. I've been hesitant
to leave them in their groups for very long .... They
probably need to be in their groups for longer, and I'm
a little reluctant to do that without having a better idea
that they will make good use of that time. (Robert)

In addition to feeling unprepared to run a class with lots of student interaction, instructors were unsure about how to assess student learning in case study instruction. Lisa taught almost exclusively with case studies, and she focused on this challenge:

I find the assessment part difficult. It's never clear to me how many of the students actually did get it. You know, when I get an answer from a group and it's right, the other ones just follow along and did they actually get it? So, I find that difficult. I also find it difficult to assess an authentic assessment. The one I've been using is, here's another article, you don't know which one, but it's in that field so you should be able to do it. That's as close, I think, as I can come to it, but usually I find that I have difficulty doing something that makes sure that they use the knowledge that they've just learned and demonstrate to me that they can do it. (Lisa)

While experienced case study instructors could describe specific teaching challenges they felt unprepared to tackle (e.g., assessment, facilitating discussion), less-experienced case study instructors expressed more general feelings of unpreparedness and associated worries:

You would think that for as long as I've been a teacher I would have more confidence in this, but I don't I know that when I'm up in front of the class, I can do a good job lecturing, a better job than the average instructor can do. I feel like I'm pretty good at that, but when lecturing is the least effective way of delivering a message, that doesn't say much. I think these case studies ... I guess I'm concerned I can go to this effort of changing what I do-and it's going to require a big effort on my part-but if the students end up feeling, well, she still is looking for one right answer, they feel like this isn't really any different, she's just trying to drag the right answer out of us, then I will feel like I haven't really accomplished what I should've. (Cheryl)

\section{New Case Study Instructors Need More Support Than Experienced Instructors}

The aim of our research is to facilitate long-term adoption of teaching strategies that produce better student outcomes than lecturing alone, and the innovation-decision model suggests that the needs of new instructors may be different from those of experienced instructors. Because our sample included both experienced case study instructors and instructors who had never used formal cases (Table 1), we sought to determine whether the factors that promote and hinder case study usage were different between these two groups.

Interestingly, we found that inexperienced and experienced instructors were more similar than different. Both groups emphasized personal experience over empirical evidence and reported that case study teaching appealed to them because it improved student learning. Instructors in both groups had supportive colleagues with whom they shared useful interactions regarding teaching, and supportive but weakly influential administrators. They also perceived similar barriers. More experience did not mitigate the tension between content coverage and case study teaching, and all instructors perceived lack of time as a barrier.

Despite these similarities, we found that instructors who had never before used case study teaching stood out in four ways. Inexperienced instructors more commonly reported that they had naturally taught in a way that aligned with case study teaching; that they were interested in case study teaching, because they were bored or otherwise dissatisfied with lecturing; that they had some unsupportive colleagues; and that they felt unprepared to manage a case study class. We present these distinctions using excerpts from an interview with an instructor whose experiences exemplified new case study teachers.

Robert learned about case study teaching and the professional development conference from a junior faculty member with whom he was scheduled to team teach a course. This junior colleague had previously attended an NCCSTS teaching professional development program, and Robert "wanted to learn what she had learned." Though Robert had not previously been exposed to formal case study teaching, he perceived that teaching techniques he had been trying were similar to cases:

Well, I didn't even know anything about this organization or any of these websites, so I've been using a lot of these techniques just kind of on my own but I didn't know what they were called. (Robert)

Robert had been trying new teaching techniques, because he was dissatisfied with lecturing: 
I just had this perception that it would be a more effective way to teach than just lecturing, which was the only model I had been exposed to, so that's what I started doing, because that's all I knew. Then after about 10 years of that, it's like, not only is this not fun anymore ... I mean, at first, you're just excited to be teaching, but after about 10 years of lecturing, I was getting bored with it, and I just thought there would be a more effective way in working with students, so I just started trying different things. (Robert)

Like most of the instructors in our sample, Robert anticipated that some of his colleagues would be supportive of his decision to integrate formal cases into his teaching, but he predicted that other colleagues would not respond as favorably. When asked why, he said, "Because I've team taught with most of them, and when I start using some of these techniques, they are not drawn to it at all. They are mostly all about content."

The prospect of unsupportive colleagues did not dissuade Robert from planning to use case studies, but he expressed more concern about his ability to manage an interactive classroom (see Robert's quote on p. 12).

Robert recognized that the conference he was currently attending and online resources, such as teaching notes, could provide some solutions to managing small-group work, but he remained concerned about this barrier.

Highly experienced instructors stood out from inexperienced instructors in two ways. They were more likely to describe increased student engagement as a positive outcome of case study teaching:

Students are far more engaged in class. Even the students that normally sit in the back corner usually have something to say when you tell them a story. They [i.e., the case studies] allow for group work, so different people [are] getting together in the classroom and talking to each other when they wouldn't be able to. (Linda)

These highly experienced instructors also were more likely to have promoted the use of case study teaching to other colleagues. One instructor described the strategy he has honed for convincing other faculty members to replace lecture time with case studies:

I've often focused on implementation just because I found two sort of attitudes among colleagues towards cases in particular and interactive teaching in general. There are some people who are willing to play with it as sort of an outside class homework assignment but not really do much with it in class, and there are also people who...even if they are intrigued by the idea, they don't have any idea how to implement it, because they see it as such a ... I've never fully understood the perspective, but they see it as like an arts and humanities type of teaching or it's too touchy-feely and I don't know how to bring that into my classroom. So, I have often focused my conversations, whether they are formal or informal presentations, on the howto-side, because ... I feel like that has been the obstacle the most of us have had. (David)

\section{DISCUSSION}

We found that personal experiences drive college biology instructors to adopt the innovation of case study teaching, to sustain case study teaching long term, and to continually work to improve their implementation of case study teaching. Most of the personal experiences we identified promote case study teaching; only three contextual factors presented significant barriers to the adoption and sustained use of case studies. In this section, we discuss the hypotheses generated by our study and potential implications for biology education research. We also reconsider the innovation-decision model that guided this work.

\section{Hypotheses That Should be Tested with Future Research}

We present here the hypotheses generated by our study and discuss the evidence supporting these hypotheses, both from our study and the broader literature. These hypotheses should not be interpreted as conclusions we are drawing about our sample or generalizations of our work to a larger population. Rather, they are hypotheses, grounded in data gathered from one sample, that we propose should be tested in a larger population and multiple samples. We also describe some implications for biology education reform that will need to be considered if future research supports our hypotheses.

Although our hypotheses derive from data about case study teaching, we propose that these hypotheses should be tested with faculty members practicing a range of active-learning strategies. Case study teaching often involves practices common in other active-learning strategies, such as small-group work and class discussions, but notably different from traditional lecturing. Therefore, we contend that our findings regarding the factors and conditions that influence biology instructors' decisions about adopting, sustaining, and improving their implementation of case study teaching may be relevant to other active-learning strategies as well. For this reason, we have worded the hypotheses using the more general term "active-learning strategies."

Hypothesis 1: In General, College Biology Instructors Make Decisions about Active-Learning Strategies Based on Their Feelings about Their Teaching; They Do Not Make Decisions Based on Empirical Data from the Literature or from Their Own Classrooms. Most biologists would agree that they strive to be objective in their research by using data to answer questions and letting evidence speak for itself. Therefore, it is reasonable to assume that biologists will accord empirical evidence similar weight in their decisions regarding teaching. Ironically, this assumption is not supported by empirical evidence. No data have been published to support the idea that college biology instructors change their teaching as a result of evidence showing the effectiveness of particular teaching strategies. In fact, this study suggests the opposite; instructors changed their teaching based on self-considerations (e.g., being bored with lecturing) and interactions with others (e.g., students who said they learn a lot more from cases than lectures).

We can generate some predictions based on the hypothesis that instructors prioritize personal evidence over empirical evidence in their decisions regarding active learning. For example, if this were true, we would predict that 1) few college science instructors access the research literature on teaching and learning college science, regardless of whether they employ active-learning strategies; 2) college science instructors 
accept or dispute empirical data about the effectiveness of active-learning strategies based on their personal perceptions of those strategies, not based on the rigor of the research, though they may rationalize their acceptance or lack thereof by citing research rigor; 3 ) college science instructors are motivated to consider adopting active-learning strategies if they feel their teaching needs to change; and 4) to sustain the use of active-learning strategies, college teachers need to feel that the strategies are making their teaching better in some way.

To our knowledge, there is not a body of research literature to address most of these predictions. However, they should be empirically tested, for example, through surveys of a broad cross section of college science faculty members (prediction 1), through an experiment linking personal perceptions of active-learning strategies to the evaluation of research literature about these strategies (prediction 2), or tracking a large sample of instructors in the process of change to identify factors associated with quitting versus persistence (prediction 4). In contrast, the research literature does address prediction 3: that college science instructors are motivated to consider adopting teaching innovations if they feel their teaching needs to change (see Introduction).

This raises a question about how instructors can be made to feel that their teaching needs to change, without damaging their sense of self-esteem. Henderson and Dancy (2008) found that some instructors were not inclined to work with physics education researchers to improve their teaching, because they felt the researchers were saying they were bad teachers. These researchers cited the theory of cognitive dissonance as an explanation for why instructors disregard the research literature on teaching (Henderson and Dancy, 2008). This theory says that humans go to great lengths to avoid dissonance between their behavior and their self-concept (Festinger, 1962). Therefore, instructors may quickly dismiss research or ideas that imply that their prior teaching had significant deficiencies.

If hypothesis 1 is supported with future research, this would have implications for biology education reform. First, we would need to actively and explicitly support instructors who are likely to feel the need for teaching support, such as instructors who are new to teaching or instructors teaching a new course, because they are most likely to be open to learning new strategies. Of course, this is not a novel idea, but good models to support new teachers are scarce. If we fail to support new teachers, they are likely to adopt status quo teaching strategies, and we may not regain the opportunity to capitalize on their sense of teaching need. Second, we would need to find ways to help instructors feel the need to constantly improve their teaching, to meet both their expectations of themselves and the expectations of others. This is an overwhelming task and will require a cultural change in the way that teaching is evaluated and rewarded by departments and institutions. Third, further empirical support for this hypothesis would suggest that reform efforts that seek to motivate change using empirical data are ineffective, unless the participants already feel that they need to change. Further research is needed to determine when in the process of incorporating active-learning strategies-if everit is effective to use empirical data to inform instructors decisions about adopting, sustaining, and improving active-learning teaching strategies.
Hypothesis 2: Resilience Is an Important Characteristic for College Biology Instructors Who Are Attempting to Incorporate Active-Learning Strategies. It is well accepted that a good scientist perseveres in spite of failure and continues to "break ground" in his or her field throughout his or her career. In contrast, a commonly promoted idea about college teaching is that an instructor can have a class "in the can" or teach on "autopilot." This attitude works against teaching reform. Any teacher who tries a new strategy will experience failure and will therefore need to revise and try again. We were pleasantly surprised to learn that some instructors in our study were realistic in their expectations about trying active-learning instruction and were committed to persist when it did not work as they hoped or intended. Researchers have documented that it is not uncommon for college instructors to try active-learning strategies but then return to their original teaching practice (e.g., Henderson et al., 2012). However, the impetus for quitting new teaching strategies requires further investigation. Additional research should assess resilience among college instructors and ask whether resilience correlates with sustained teaching reform.

On the basis of the hypothesis that resilience is an important characteristic for trying and sustaining active-learning strategies, we predict that 1) instructors who expect to try a new strategy, identify problems with their implementation, and try again will be more likely to continue using an active-learning strategy than instructors who have not considered the high potential for failure with a new strategy before they attempt to use the strategy; and 2) a willingness to try and fail may be associated with an instructor's self-efficacy in teaching, meaning that instructors with lower self-efficacy as teachers would be more likely to try and then abandon a new teaching strategy than those with high self-efficacy.

If, indeed, resilience is found to be an important characteristic for college biology instructors implementing active-learning strategies, teaching professional development should facilitate the acquisition of resilience. That is, teaching professional development programs should put forth the model that failure with a new teaching innovation is to be expected and that the development of skills critical to a new innovation, such as questioning, leading discussions, or facilitating small-group work, require repeated practice with feedback. Given the predictions of hypothesis 1, these professional development programs likely will build resilience if they are structured so that instructors who are new to active learning have the opportunity to interact with colleagues who share anecdotes about failure, not just success, with active learning.

Finally, if hypothesis 2 is supported, colleagues and administrators should be expected to be tolerant-even sympathetic - of fluctuations in student and peer teaching evaluations resulting from changes to active learning. Instructors who are trying to improve their teaching by implementing active-learning strategies are likely to be more resilient if they do not feel pressured by unrealistic expectations for effortless perfection.

Hypothesis 3: Perceptions of Improved Student Outcomes Facilitate Sustained Use of Active-Learning Teaching Strategies. Instructors in our study reported observing favorable student outcomes resulting from case study instruction, 
including engagement, learning, skill development, and acceptance of active-learning teaching strategies. These perceptions strongly influenced instructors' feelings about case study teaching and, in turn, their interest in continuing to use case studies. Instructors spoke with excitement about student behavior and student work resulting from their implementation of case study instruction. Interestingly, a few positive interactions with or observations of students regarding case study instruction seemed to be sufficient to convince instructors of the value of case study teaching. In fact, instructors who reported favorable student outcomes also commonly mentioned that they had experienced some student resistance to their use of case studies. Instructors were willing to accept that some students would be unhappy with case study teaching, as long as they also perceived that some students responded positively.

This hypothesis suggests at least two predictions that require further investigation: 1) Instructors who engage with students as part of their implementation of active-learning instruction-through in-class interactions, solicited feedback, collected student work-would be more likely to continue using active-learning strategies, because they would be more likely to perceive changes in student outcomes. In contrast, instructors who try to implement an active-learning strategy without the interactive components, such as using peer instruction without peer discussion, may perceive less benefit and therefore be more likely to quit. 2) We predict that a lack of training in implementing active-learning instruction may increase the likelihood of quitting, because unsuccessful implementation would not lead to perceptions of improved student outcomes.

If further investigations supported hypothesis 3, instructors should be taught how to monitor students for indications of teaching effectiveness. Reflecting on one's teaching is a mechanism for generating knowledge from experience and should therefore facilitate the development of effective active-learning instructors. Instructors in our study were already in the habit of monitoring students, but maximizing the utility of monitoring requires knowing which cues to evaluate and then doing so. In particular, highly effective college instructors continually monitor students throughout class, detecting verbal, nonverbal, and written cues, as well as the absence of cues, and evaluating these cues for evidence of student learning (McAlpine et al., 1999). In contrast, novice teachers tend to focus on their behavior as the teacher, rather than on student behavior and learning (Borko and Livingston, 1989). Effectively monitoring students may be especially important in active-learning classrooms, where students are asked to work rather than simply listen. Teaching professional development may be able to facilitate the development of effective active-learning instructors by helping them develop the ability to skillfully detect cues from students. For example, cues about what groups of students are doing, where students are struggling, and how student work is progressing are important in active learning (Winter et al., 2001).

Hypothesis 4: Viewing Colleagues as Resources for Teaching Will Facilitate Sustained and Effective Active-Learning Instruction. Biologists are highly collaborative in their research. Rarely is a research article written by only one author published in Science or Nature. We can therefore assume that college biology instructors are capable of working collaboratively and also recognize the immense advantages of working with groups of colleagues. Unfortunately, the mentality that "two heads are better than one" has not been widely transferred from biology research to biology teaching. Instructors often not only teach alone, they also design and plan their courses and lessons individually and receive and interpret feedback from student and peer evaluations in isolation. While research collaborations are expected, supported, and brokered by mentors and colleagues, teaching collaborations do not receive the same attention.

Despite having colleagues who were mostly supportive of case study teaching, most participants in our study were not taking full advantage of their colleagues as a resource to address their questions about case study teaching. One striking example of this was revealed when we asked participants if they had ever seen anyone else implementing case study teaching. Almost none of our participants had ever seen another instructor use case study teaching in a college classroom, though greater than half had colleagues who used case studies. Interestingly, instructors were surprised by this question. Few had ever considered the possibility of observing another instructor using case studies, yet upon considering this in the interview, they recognized potential value in this exercise. Some also seemed amused that the idea of observing another instructor had not previously occurred to them. We interpret this as evidence of a culture surrounding college teaching that is highly "privatized," by which we mean teaching is conducted in the privacy of one's classroom with little input or output among teachers, so much so that it is a foreign and novel idea that a college instructor would seek to improve his or her teaching by observing other instructors.

Several predictions follow from the hypothesis that viewing colleagues as resources facilitates active-learning instruction: 1) Instructors who engage in meaningful interactions with colleagues about teaching will be more likely to sustain active-learning instruction and to implement effectively. This prediction could be examined using social network analyses of instructors within departments and institutions (learn about this approach in Grunspan et al., 2014). 2) Teaching professional development that facilitates the development of long-term relationships among instructors will be more likely to produce instructors who sustain the use of active learning instruction. 3) Instructors who teach a class in collaboration with another instructor and undertake integrating active-learning instruction together will be more likely to succeed than instructors who lack close colleague support.

If hypothesis 4 withstands testing in broader samples of instructors, one implication for biology education reform would be that instructors need help connecting with their colleagues regarding teaching. One type of program that could accomplish this is faculty learning communities (FLCs; Cox, 2004). FLCs are small groups of faculty members-typically within one institution-who work together over an extended period of time in the pursuit of improving their teaching (Cox, 2004). Ideally, members of an FLC receive support and feedback from one another as they strive to achieve personal goals. Though instructors may continue to teach individually, FLCs could provide the opportunity to experience many of the benefits of collaborations, including constructive feedback, synergistic creativity, diverse perspectives, 
and personal support. At least one study has demonstrated that FLCs are associated with improved student learning (Cox, 2004). Additionally, FLCs align with recommendations for teaching professional development for college STEM instructors (Henderson et al., 2011). These recommendations derive from a literature review that found interventions designed to facilitate instructional change among instructors are most successful if they last a semester or longer, focus on changing instructors' conceptions of teaching and learning, and mesh with the system in which an instructor works (Henderson et al., 2011). Additional research is necessary to determine the impact of FLCs on instructor practice and student outcomes. Research is also needed to understand what resources are especially critical for instructors to receive from interacting with their peers on the topic of teaching. Another challenging area in need of research is how the environment in which instructors work can be modified to encourage collaborative teaching, including everything from physical space to collegial attitudes about teaching.

\section{Modifying the Innovation-Decision Model}

On the basis of this research, we propose modifying the innovation-decision model to tailor it to the specific case of college biology instructors changing their teaching to incorporate active-learning strategies (Figure 3). The changes we propose are not criticisms of the original model but specializations for our context.

The first modification we propose is to specify "dissatisfaction" as a prior condition that leads a college biology instructor to move from not changing his or her teaching to changing his or her teaching (Figure 3). Like other researchers, we found that feeling dissatisfied with one's experience of teaching or one's self-image as a professional teacher precedes the decision to incorporate active learning (e.g., Gess-Newsome et al., 2003; Bouwma-Gearhart, 2012). In our data set, the most significant dissatisfaction was with lecturing, because instructors considered it to be boring for them or their students. We suggest that instructors who feel satisfied with their performance (e.g., who think they are great lecturers and that students learn a lot from their lectures) are less likely to adopt active-learning strategies or change their teaching in any substantial manner.

While dissatisfaction is a necessary prior condition for college biology instructors to change their teaching, we do not think it is a sufficient prior condition. Rather, our data suggest that instructors change their teaching when they are dissatisfied and when their circumstances cause or allow changing to become a priority (Figure 3). Because all instructors have a finite amount of time they can dedicate to their work, it is more useful to think of lack of time for a task as lack of prioritization of the task. Instructors who say they have insufficient time to plan and implement active learning are revealing that the environment in which they work (e.g., job responsibilities and expectations, review and reward policies), their past experiences, and their own attitudes and preferences have led them to decide to prioritize other work. For example, one participant in our study had been dissatisfied with his teaching (i.e., lecturing only) for quite some time, but he did not seek to make changes until other parts of his job eased and a coinstructor explicitly asked for support with curriculum development. Likewise, another participant had heard about case study teaching more than $15 \mathrm{yr}$ before our interview with her, and she had considered using case studies, because of her severe dissatisfaction with students' responses to her teaching. But she did not make plans to start using case studies until, after two previous attempts, she was finally able to attend the professional development conference where we interviewed her. It seems that instructor dissatisfaction can remain latent for long periods of time if the context does not facilitate change.

Another modification that we have made to the model is to combine the persuasion and decision stages. In talking about their experiences with case study teaching, instructors were unable to distinguish between forming an attitude (i.e., persuasion stage) and deciding to use case study teaching. This may be because instructors moved quickly from one stage to the other, or it may be because instructors who currently have positive attitudes about an innovation cannot recall a time when they had a neutral or negative attitude toward that innovation. While distinguishing these stages may be theoretically useful, disentangling them empirically proved challenging. Future work that tracks instructors through the change process may provide more insight into this issue.

We also propose renaming the confirmation stage as the reflection stage. While the term confirmation implies some degree of finality, reflection implies personal rumination that lacks a distinct endpoint. Therefore, it better captures the iterative nature of the change in which these instructors engaged. The change from confirmation to reflection also serves to better align the model with an important construct from the education literature, reflective teaching. Reflective teaching practices are those in which an instructor consistently applies a critical lens to his or her teaching, with the goal of learning from and about his or her teaching experiences and then linking it to future action (McAlpine and Weston, 2000).

A commonly identified characteristic of highly accomplished and effective instructors is regular, purposeful reflection on their teaching (e.g., Kane et al., 2004), but not all teacher reflection leads to improved student learning. After examining exemplary college instructors, McAlpine and Weston (2000) generated a list of distinguishing features of

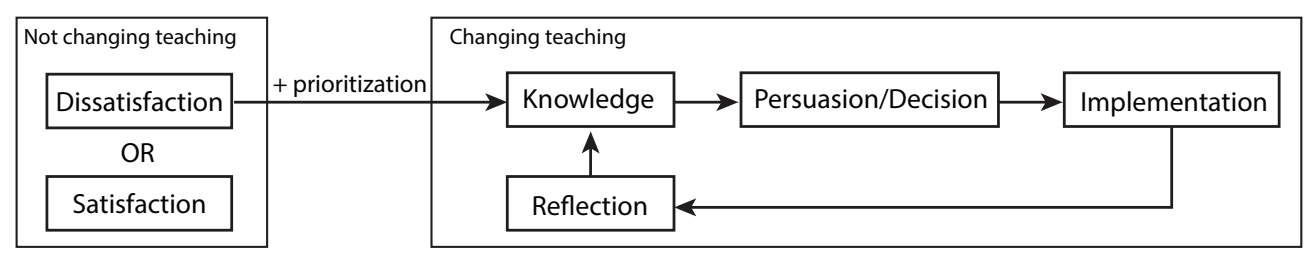

Figure 3. Innovation-decision model modified to represent the process by which college biology instructors adopt, sustain, and improve their implementation of teaching innovations. 
instructors who engage in reflection that leads to better teaching. Interestingly, the list aligns with some of our observations of college biology instructors. Distinguishing features of teachers who engage in effective reflection include: a recognition that they need pedagogical knowledge in addition to content knowledge to be effective teachers; a willingness and ability to try and fail; the perception of minimal contextual constraints; engagement in frequent practice; and some minimal level of knowledge about teaching from which to build (McAlpine and Weston, 2000). The alignment between these features and what we observed in our study suggests that the instructors we studied were poised to improve student learning through reflection and would have benefited from encouragement and support for reflective practices.

Perhaps the most important modification we suggest making to the innovation-decision model is transforming it from a linear to cyclical process. We have made this change because instructors in our study did not undertake wholesale adoption and then cease to change, such as transforming an entire course to be case-based in one semester and then continuing to teach that course essentially the same way year after year. Rather, they continually made small changes to their instruction, often over many years. They may have started by incorporating one case study in a class. The following year, they may have revised how they implemented that case and added another. Many instructors in our study seemed to be cycling through this process indefinitely, demonstrating motivation, dedication, persistence, and resilience. We have illustrated the cyclical nature of the innovation-adoption process by linking the implementation stage to the reflection stage, and the reflection stage to the knowledge stage. Well-timed, evidence-based teaching professional development could have a substantial impact on whether instructors in this cycle are able to improve student learning using active-learning strategies.

Our modified innovation-decision model not only explains and synthesizes our data with previous research but also suggests at least two future directions. First, future research should distinguish between the first and subsequent cycles through the stages of knowledge-persuasion/decision-implementation-reflection. Some participants in our study were brand-new to case study teaching, so they were going through the cycle for the first time. But other participants had been using case studies for years, so they had repeatedly gone through this cycle. It is possible that perceptions of success during the first cycle are especially critical to remaining in the change cycle (i.e., sustaining and improving). Future research should explore this possibility.

Second, future research should distinguish between low-quality and high-quality reflection and its relationship to improving student outcomes. While all instructors likely reflect on their experiences implementing an active-learning strategy, they certainly vary in how long they reflect, the types of information they use as they reflect, whether they reflect alone or with colleagues, what kind of outside knowledge they seek, and so on. We suspect that the quality of reflection practices and implementation quality are linked. That is, high-quality reflection leads to more pertinent and accurate knowledge about teaching and learning (e.g., how in-class discussion impacts student learning of a challenging concept), which in turn leads to better decisions about implementation and more improvement in student outcomes. The idea that a causal link exists between instructor reflection, instructor knowledge building, and student learning should be tested.

Additionally, though we investigated biology teachers, we suspect that instructors in other STEM disciplines are also influenced by personal experiences. Future work should investigate similarities and differences in the process of adopting a new teaching innovation when the innovation and the instructor's discipline vary. To broadly improve biology education, we must understand how to support instructors in order to effectively implement active learning. The work described here provides a revised model for thinking about the process by which instructors reform their teaching. This work also generates testable hypotheses about that process and about how teaching professional development can support instructors throughout the process of adopting, sustaining, and improving active-learning teaching. Our work takes one more step toward making efforts to reform teaching-not just the reformed strategies themselves-evidence based.

\section{ACKNOWLEDGMENTS}

We thank the participating instructors for their time and willingness to discuss their experiences. We thank Clyde F. Herreid, Nancy Schiller, Carolyn Wright, and the NCCSTS for acting as a liaison between the authors and conference participants, for opening an NCCSTS conference to our study, and for continued support for research questions about how college biology instructors can best be supported to improve student outcomes. Thank you also to the Biology Education Research Group at the University of Georgia, who improved the quality of this work with critical feedback, high standards, and endless support. Thank you to Rebecca M. Price for her critical review of the manuscript. Thank you to the monitoring editor and anonymous reviewers whose insightful feedback greatly improved our manuscript. Resources for this research were provided by the University of Georgia and the NCCSTS.

\section{REFERENCES}

American Association for the Advancement of Science (2011). Vision and Change in Undergraduate Biology Education: A Call to Action, Washington, DC.

Andrews T, Leonard M, Colgrove C, Kalinowski S (2011). Active learning not associated with student learning in a random sample of college biology courses. CBE Life Sci Educ 10, 394-405.

Borko H, Livingston C (1989). Cognition and improvisation: differences in mathematics instruction by expert and novice teachers. Am Educ Res J 26, 473-498.

Bouwma-Gearhart J (2012). Research university STEM faculty members' motivation to engage in teaching professional development: building the choir through an appeal to extrinsic motivation and ego. J Sci Educ Technol 21, 558-570.

Boyer Commission on Education Undergraduates in the Research University (1998). Reinventing Undergraduate Education: A Blueprint for America's Research Universities, Stony Brook: State University of New York.

Brownell SE, Tanner KD (2012). Barriers to faculty pedagogical change: lack of training, time, incentives, and ... tensions with professional identity? CBE Life Sci Educ 11, 339-346.

Charmaz K (2006). Constructing Grounded Theory: A Practical Guide through Qualitative Analysis, London: Sage.

Cox MD (2004). Introduction to faculty learning communities. New Direct Teach Learn 2004, 5-23. 
Dancy M, Henderson C (2010). Pedagogical practices and instructional change of physics faculty. Am J Phys 78, 1056-1063.

Dinan F (2002). Chemistry by the case. J Coll Sci Teach 32, 36-41.

Ebert-May D, Derting TL, Hodder J, Momsen JL, Long TM, Jardeleza SE (2011). What we say is not what we do: effective evaluation of faculty professional development programs. BioScience $61,550-558$

Festinger L (1962). A Theory of Cognitive Dissonance, vol. 2, Redwood City, CA: Stanford University Press.

Gabel C (1999). Using case studies to teach science. Paper presented at the Annual Meeting of the National Association for Research in Science Teaching, March 28-31, 1999, Boston, MA.

Gess-Newsome J, Southerland SA, Johnston A, Woodbury S (2003). Educational reform, personal practical theories, and dissatisfaction: the anatomy of change in college science teaching. Am Educ Res J $40,731-767$.

Glynn SM, Taasoobshirazi G, Brickman P (2007). Nonscience majors learning science: a theoretical model of motivation. J Res Sci Teach 44, 1088-1107.

Grunspan DZ, Wiggins BL, Goodreau SM (2014). Understanding classrooms through social network analysis: a primer for social network analysis in education research. CBE Life Sci Educ 13, 167-178.

Hall G, Loucks S (1978). Teacher concerns as a basis for facilitating and personalizing staff development. Teach Coll Rec 80, 36-53.

Handelsman J, Ebert-May D, Beichner R, Bruns P, Chang A, DeHaan R, Gentile J, Lauffer S, Stewart J, Tilghman SM (2004). Scientific teaching. Science 304, 521-522.

Henderson C (2005). The challenges of instructional change under the best of circumstances: a case study of one college physics instructor. Am J Phys 73, 778-786.

Henderson C, Beach A, Finkelstein N (2011). Facilitating change in undergraduate STEM instructional practices: an analytic review of the literature. J Res Sci Teach 48, 952-984.

Henderson C, Dancy MH (2008). Physics faculty and educational researchers: divergent expectations as barriers to the diffusion of innovations. Am J Phys 76, 79-91.

Henderson C, Dancy M, Niewiadomska-Bugaj M (2012). Use of research-based instructional strategies in introductory physics: where do faculty leave the innovation-decision process? Phys Rev ST Phys Educ Res 8, 020104.

Herreid CF, Schiller NA, Herreid KF (2011). Science Stories: Using Case Studies to Teach Critical Thinking, Arlington, VA: NSTA Press.
Herreid CF, Schiller NA, Herreid KF (2014). Science Stories You Can Count On: 51 Case Studies with Quantitative Reasoning in Biology, Arlington, VA: NSTA Press.

Kane R, Sandretto S, Heath C (2004). An investigation into excellent tertiary teaching: emphasizing reflective practice. High Educ 47, 283-310.

Lundeberg MA, Levin BB, Harrington HL (1999). Who Learns What from Cases and How? The Research Base for Teaching and Learning with Cases, Mahwah, NJ: Routledge.

Lundeberg MA, Scheurman G (1997). Looking twice means seeing more: developing pedagogical knowledge through case analysis. Teach Teach Educ 13, 783-797.

Mazur E (1997). Peer Instruction, Upper Saddle River, NJ: Prentice Hall.

McAlpine L, Weston C (2000). Reflection: issues related to improving professors' teaching and students' learning. Instr Sci 28, 363-385.

McAlpine L, Weston C, Beauchamp C, Wiseman C, Beauchamp J (1999). Monitoring student cues: tracking student behaviour in order to improve instruction in higher education. Can J High Educ $29,113-144$.

National Research Council (NRC) (1997). Science Teaching Reconsidered: A Handbook, Washington, DC: National Academies Press.

NRC (2012). Discipline-based Education Research: Science and Engineering, Washington, DC: National Academies Press. www.nap.edu/openbook.php?record_id $=13362 \& p a g e=1$ (accessed 6 December 2013).

Patton MQ (1990). Qualitative Evaluation and Research Methods, Newbury Park, CA: Sage.

President's Council of Advisors on Science and Technology (2012). Engage to Excel: Producing One Million Additional College Graduates with Degrees in Science, Technology, Engineering, and Mathematics, Washington, DC: U.S. Government Office of Science and Technology.

Rogers E (2003). Diffusion of Innovations, New York: Free Press.

Saldaña J (2013). The Coding Manual for Qualitative Researchers, Thousand Oaks, CA: Sage.

Turpen C, Finkelstein ND (2009). Not all interactive engagement is the same: variations in physics professors' implementation of peer instruction. Phys Rev Spec Top Phys Educ Res 5, 020101.

Wieman C, Deslaurier L, Gilley B (2013). Use of research-based instructional strategies: how to avoid faculty quitting. Phys Rev Spec Top Phys Educ Res 9, 023102.

Winter D, Lemons P, Bookman J, Hoese W (2001). Novice instructors and student-centered instruction: Identifying and addressing obstacles to learning in the college science laboratory. J Scholarship Teach Learn 2, 15-42. 